\title{
Variación léxica según las generaciones en el lenguaje hablado de Guadalajara [2]
}

$\mathrm{E}$ ste estudio sociolingüístico es una serie de trabajos realizados sobre la variación léxica según las generaciones en el lenguaje hablado de la ciudad de Guadalajara, cuya ponencia se expuso el 19 de julio de 2004, en el XV Congreso de la Asociación Internacional de Hispanistas, en el Tecnológico de Monterrey, Nuevo León, México. En las investigaciones tratamos de identificar la posible variación léxica según la edad en el habla de Guadalajara con respecto a los 18 ítems de la 'apariencia y características físicas' ${ }^{1}$ En la ponencia arriba mencionada, sin embargo, nos vimos obligados a limitar el contenido hasta el ítem 12 por cuestiones de tiempo y del reglamento de la publicación de las actas del mismo congreso ${ }^{2}$ y, como consecuencia, la conclusión tal vez haya resultado tentativa.

En este estudio nos dedicaremos únicamente a hacer análisis de los datos obtenidos del ítem 13 al 18: /nariz alta/ - Inariz baja/, /boca grande / - /boca chical, /busto grande + /busto chicol, /vientre grande / /vientre chicol, /piernas gordas/ - /piernas delgadas / y pies grandes / - pies pequeños /. Con respecto a los antecedentes de los estudios relacionados y la metodología de nuestra investigación se podrá consultar en dichas actas.

\section{Resultado y análisis de los datos}

\section{3. / nariz alta / - / nariz baja /}

$\mathrm{Al}$ referirse a la 'nariz de tamaño mayor' de una persona, la respuesta que obtuvimos de manera predominante es narizón que prefirieron hasta un $87 \%$ de los informantes jóvenes, un $66.7 \%$ de los hablantes de la segunda generación y un $53.8 \%$ de los mayores de edad. Es-

\footnotetext{
* Investigador del Departamento de Estudios del Pacífico, de la Universidad de Guadalajara.
}

tas cifras pueden indicar que narizón va a ser la forma de la norma linguiística tapatía. Luego le sigue narigón con un $3 \%$ en la primera generación, un $25 \%$ en la segunda y un $23.1 \%$ en la tercera. Desde el punto de vista del estrato social, Garza Cuarón nos muestra datos interesantes al respecto, según los cuales el término narizón es preferido por los informantes oaxaqueños del nivel bajo, mientras que narigón lo usan los informantes del nivel alto. ${ }^{3}$ Aunque la mayoría de nuestros informantes pertenezcan al nivel alto o medio, no es sorprendente esta discordancia preferencial, sino que quizá se deba a cierta diferencia dialectal. De todas maneras, en el presente trabajo no profundizaremos en este aspecto.

Como concepto contrario de las mencionadas expresiones, el adjetivo que modifica a nariz con más preferencia fue pequeña con un $36 \%$ de los jóvenes y un $28.6 \%$ en la segunda y la tercera generación, respectivamente. Es sumamente interesante observar que prefirieron usar el vocablochato o chatito un $64.3 \%$ de la tercera generación, un $42.9 \%$ de la segunda y un $21 \%$ de la primera. Aunque supuestamente esta voz sea común en México, Centroamérica y las Antillas, ${ }^{4}$ ¿en el habla tapatía será arcaica en un futuro no muy lejano?

\section{4. / boca grande / - / boca chica /}

Con respecto a la 'boca de tamaño mayor' de alguien, se obtuvieron respuestas mayoritarias a favor de bocón, con un $39 \%$ en la primera generación, un $69.2 \%$ en la segunda y un $53.8 \%$ en la tercera, aunque a veces se usara con valor de 'hablador o mentiroso'; sin embargo, dicho uso no excede del sistema del español porque el aumentativo -ón puede referirse al aumento de dimensiones. Según las cifras, la frecuencia de dicho vocablo es la más notoria en la generación de edades intermedias, quizá porque haya sido una norma para 
esa generación. Usaron también un $5 \%$ de los jóvenes y un $15.4 \%$ de las generaciones mayores el vocablo trompudo, que seguramente se aplicaba por analogía conceptual con esa parte de los animales. Los demás informantes prefirieron la forma «boca + calificativo», en especial boca grande con un $28 \%$ en los jóvenes, con un $15.4 \%$ en la segunda generación y con un $23.1 \%$ en la tercera.

Como antónimo de bocón se registró boquita sólo en un 7\% en la primera generación y en un $8.3 \%$ en la segunda y la tercera generación. Esto se debe probablemente a que en México se usan en muchos casos los diminutivos más bien con valor afectivo. El uso predominante fue de la forma boca chica o chiquita, la cual usaron un 50\% de los informantes en todas las generaciones. Luego le sigue la frase boca pequeña, usada por $27 \%$ de los jóvenes y $33.3 \%$ de las dos generaciones mayores.

\section{5. / busto grande / - / busto chico /}

Para designar a una mujer con 'busto de mucho volumen', sorprendentemente un 59\% de los jóvenes prefirieron usar la voz chichona,$^{5}$ la cual se puede considerar como mexicanismo, pero este uso puede ser un poco popular o, más bien, común entre los jóvenes, ya que en la segunda generación se presentó un $17.6 \%$ de frecuencia y en la tercera, un $13.3 \%$. Este hecho lingüístico, en otros términos, coincide con el fenómeno de "mayor conservadurismo en el empleo de palabras tabuizadas en las generaciones mayores". ${ }^{6}$ Luego le siguen de importancia bustona y pechugona, usadas muy probablemente por analogía física con el pecho de las aves. Tememos que el término académicobustona y la forma humorística pechugona estén en vías de desuso, ya que bustona la usaron un $33.3 \%$ de la tercera generación, un $17.6 \%$ de la segunda y tan sólo un $3 \%$ de la primera; pe- chugona, a su vez, fue empleada por un $13.3 \%$ de la tercera generación, un $11.8 \%$ de la segunda y un $9 \%$ de la primera.

En el caso contrario, la palabra predominante fue plana, cuyo uso alcanzó un $40 \%$ en la gente joven, un $28.6 \%$ en la generación de edades intermedias y un $7.1 \%$ en los hablantes mayores de edad. Esta tendencia muestra que este uso quizá va adquiriendo la norma lingüística en la zona metropolitana tapatía. Hubo informantes que prefirieron usar la construcción «busto + calificativo», comobusto pequeño, busto chico, poco busto, etcétera, cuyos casos alcanzaron apenas un $13 \%$ en la primera generación, un $7.1 \%$ en la segunda y un $21.4 \%$ en la tercera. Los que mostraron preferencia por "pecho + calificativo»:pechos chicos, pecho pequeño, poco pecho, etcétera, tampoco fueron de mucha importancia, ya que la primera generación obtuvo un $3.3 \%$; la segunda, un $28.6 \%$, y la tercera, $14.3 \%$, respectivamente.

\section{6. / vientre grande / / vientre chico /}

$\mathrm{Al}$ tratarse de alguien con 'vientre voluminoso', predominó la voz panzón que fue empleada por $56 \%$ de los jóvenes, $56.3 \%$ de la segunda generación y $60 \%$ de la tercera. En este caso podremos considerar dicho vocablo como preferido por los tapatíos en general. Otra palabra similar puede ser barrigón, aunque parece más coloquial de acuerdo con la RAE. ${ }^{7} \mathrm{El}$ porcentaje registrado en este vocablo fue más bajo de lo que se esperaba: en los hablantes mayores de edad hubo un $20 \%$, en los de edades intermedias, un $12.5 \%$, pero en los jóvenes no hubo ningún caso. La tendencia decreciente total hacia la generación joven podría indicar una posible desaparición de este vocablo de uso familiar.

La palabra gordo fue registrada con un $24 \%$ en la primera generación, un $12.5 \%$ en la 
segunda y un $6.7 \%$ en la tercera. El porcentaje más alto del uso de este término en los jóvenes tal vez parezca un poco sorprendente a primera vista; sin embargo, en comparación con panzón o barrigón, la palabra gordo puede contar con un valor más amplio semánticamente. Una de las características lingüísticas de los jóvenes es el "uso abusivo de términos indefinidos" como lo afirman López Morales y Rector. ${ }^{8}$

Como casos del significado contrario, la voz que con más incidencias se registró fue delgado o delgadito, con un $46 \%$ en la primera generación, con un $26.7 \%$ en la segunda y con un $30.8 \%$ en la tercera. Luego le sigue flaco, quizá preferida por el sexo masculino, con un $14 \%$ en la primera generación, con un $26.7 \%$ en la segunda y con un $7.7 \%$ en la tercera. Aparte de estos vocablos, no encontramos ninguna palabra o expresión significativa para designar con exactitud esta naturaleza física. En realidad hubo pocos casos al respecto, como panza (o estómago) de lavadero, pancita, acinturado, etcétera.

\section{7. / piernas gordas / - / piernas delgadas /}

Para referirse a alguien con las 'piernas medio llenas', la mayoría de los informantes dieron mayor preferencia a piernudo, con un $67 \%$ en la primera generación, con un $66.7 \%$ en la segunda y con un $63.6 \%$ en la tercera, respectivamente. Se podrá decir, de acuerdo con los datos, que esta voz está bastante generalizada en la ciudad de Guadalajara. Según Kany, ${ }^{9}$ el sufijo -udo en América tiene mayor matiz despectivo o vulgar; sin embargo, no nos parece que piernudo se use con el mismo valor en México, al menos en Guadalajara. Hubo pocos casos en que se usaban otros aumentativos. En la generación de edades intermedias hubo ciertas incidencias de (una) piernudota como sustantivo, con un $16.7 \%$ de frecuencia.

Para hablar del caso contrario, se presentó cierta sintomatología léxica, en la cual destacó la construcción "piernas + calificativo" o «piernas de + sustantivo». Pronunciaron piernas flacas el $29 \%$ de los jóvenes, el $23.1 \%$ de los de edades intermedias y el $30.8 \%$ de los mayores de edad, respectivamente. Después le sigue de importancia piernas delgadas, con un $12 \%$ en la primera generación y con un $23.1 \%$ en las generaciones mayores. Es interesante encontrar el uso de piernas de chorro o de chorro de atole únicamente en la generación de los mayores de edad, con un $15.4 \%$, aunque esta cifra no pueda ser cuantitativa. A pesar del porcentaje no totalmente confiable de dicha expresión, esto nos puede mostrar cierta diferencia de los hábitos alimenticios entre las generaciones más jóvenes y el tercera generación, puesto que en la primera y la segunda generación prefirieron usar piernas de popotitos, con un $9 \%$ (en la primera) y con un $7.7 \%$ (en la segunda).

\section{8. / pies grandes /- / pies pequeños /}

Con respecto a la persona que tiene 'pies de mayor tamaño', el uso predominante de los tapatíos a través de todas las generaciones fue del vocablo patón, empleado por $74.0 \%$ de los jóvenes, un $100 \%$ en la segunda generación y un $61.5 \%$ en la tercera. De acuerdo con el resultado, esta forma la podremos considerar como una norma lingüística actual dentro de la zona metropolitana de Guadalajara, no sólo por su porcentaje frecuencial, sino debido a que el uso se encuentra concentrado en la generación de edades intermedias, uno de los grupos sociales más importantes desde el punto de vista sociolingüístico y socioeconómico. La voz patudo apenas alcanzó a un 3.0\% en los jóvenes, aunque en teoría hubiera sido más frecuente el uso. Hubo algunos informantes que prefirieron decir pie (s) grande (s), con un $16.7 \%$ en la primera generación y con un $38.5 \%$ en la tercera, pero no parece de mayor importancia.

En caso contrario, fue predominante la respuesta con la forma "pies + calificativo». En pies chicos (o chiquitos) encontramos un $42 \%$ de frecuencia en la generación de los jóvenes, un $30.8 \%$ en la segunda generación y un $33.3 \%$ en la tercera. Luego le sigue de importancia pies pequeños, aunque se considere prácticamente como expresión sinónima, con un $26 \%$ en la primera generación, un $30.8 \%$ en la se- 
gunda y un $25 \%$ en la tercera, respectivamente. El uso de los diminutivos (ej.piecitos(s), piececito o patita) resultó menos frecuente de lo que se esperaba: en los jóvenes el empleo de los diminutivos apenas alcanzó $16 \%$, en los de edades intermedias, un $15.4 \%$, y en los mayores de edad, un $16.7 \%$. Este resultado coincide con el estudio de Ávila, ${ }^{10}$ quien afirma que sociolingüísticamente no existe variación. A nuestro parecer, para referirse al 'tamaño o talla menor de la(s) parte(s) del cuerpo de una persona', la tendencia de evitar el uso del diminutivo puede ser bastante común en algunos ítems que acabamos de ver.

\section{Conclusiones}

Ya que hemos llegado en forma tentativa a una conclusión en el trabajo anterior de la misma serie, habrá que mencionar que éstas son unas conclusiones complementarias, en especial sobre los ítems del número 13 al 18 de nuestro cuestionario.

Los términos narizón, chichona y plana quizá puedan adquirir la norma lingüística por lo menos dentro de la zona metropolitana de Guadalajara, ya que el uso de dichas palabras se va generalizando en las generaciones más jóvenes, según muestran los datos obtenidos. En especial, la voz popular chichona es probable que reemplace al término académico bustona y otro humorísticopechugona. Lo mismo parece estar sucediendo con el vocablo narizón, quizá con más vigor sociolingüístico. La voz narigón en el habla de Guadalajara, según los datos, tal vez esté en desuso en un futuro no muy lejano. También es importante advertir que algunas voces con cierto matiz humorístico como chato y probablemente bustona, pechugona, trompudo y barrigón se encuentran ya en vías de desuso.

Al observar desde el aspecto semántico todas las voces y expresiones registradas, lo más interesante es que la designación del tamaño o talla menor de la(s) parte(s) del cuerpo, en la mayoría de los casos, no acude a un solo calificativo o sustantivo, sino a la construcción «sustantivo + calificativo», incluyen- do ojos pequeños, tal como nariz pequeña, boca chica, busto chico, piernas delgadas, pies pequeños, etcétera. Independiente de estos rasgos físicos de una persona, es indudable que tanto en el español de México como en el de otros países de habla hispana existe variación sociolingüística más vigorosa a nivel léxico que a otros niveles lingüísticos.

\section{Notas}

1 Los ítems en cuestión son /desnudo/, /mojado/, /suciol, |sanol, /cansado/, |blanco - moreno - rubiol, / gordo - delgadol, lalto - bajol, lguapo - feol, kcalvo cabelludo /, |rizado - lacio /, lojos grandes - ojos pequeños l, Inariz alta - nariz bajal, /boca grande - boca chical, busto grande - busto chicol, tvientre grande vientre chico /, /piernas gordas - piernas delgadas / y / pies grandes-pies pequeños \%

2 Daisuke Kishi. "Variación léxica según las generaciones en el lenguaje hablado de la ciudad de Guadalajara", Actas del XV Congreso de la Asociación Internacional de Hispanistas, Monterrey, México (en imprenta).

3 Beatriz Garza Cuarón. El español hablado en la ciudad de Oaxaca, México. México: El Colegio de México, 1987, p. 62.

4 Francisco J. Santamaría. Diccionario general de americanismos. Tomo I, Villahermosa: Gobierno del Estado de Tabasco, 1988, p. 475.

5 Real Academia Española, Diccionario de la lengua española. Tomo I, Madrid: Ed. Espasa Calpe, 2001, p. 526. Parece ser también común en Centroamérica ( $\mathrm{Pa}-$ blo Grosschmid y Cristina Echegoyen. Diccionario de regionalismos de la lengua española Barcelona, Ed. Juventud, 1998, p. 162). Etimológicamente es más probable que esta voz se derive de chichis (de origen náhuatl) que significa 'busto o pechos'.

6 Humberto López Morales. Sociolingüística. Madrid:Ed. Gredos, 1989, p. 117.

7 Real Academia Española. Diccionario de la lengua española. Tomo I, Madrid: Ed. Espasa Calpe, 2001, p. 294.

8 Humberto López Morales, op. cit., p. 117. Mónica Rector. A linguagem da juventude. Petrópolis, Ed. Vozes Ltd., 1975, p. 202.

9 Charles E. Kany.Semántica hispanoamericana. Madrid: Aguilar, 1969, pp. 129-130.

10 Raúl Ávila. El habla de Tamzunchale. México: El Colegio de México, 1990, p. 94 . T: 